\title{
O REPOSITÓRIO DE CONTEÚDO DIGITAL NAS PESQUISAS DE HISTÓRIA DA EDUCAÇÃO MATEMÁTICA
}

\author{
David Antonio da Costa \\ Universidade Federal de Santa Catarina/UFSC \\ david.costa@ufsc.br \\ Wagner Rodrigues Valente \\ Universidade Federal de São Paulo/UNIFESP \\ wagner.valente@unifesp.br
}

\begin{abstract}
RESUMO
Este texto ${ }^{1}$ apresenta o Repositório de Conteúdo Digital utilizado pelo GHEMAT - Grupo de Pesquisa de História da Educação Matemática. Este espaço virtual, sediado fisicamente na Universidade Federal de Santa Catarina, abriga as digitalizações dos documentos mobilizados nos projetos em andamento deste grupo de pesquisa. O seu uso tem se demonstrado profícuo pois permite o compartilhamento destas fontes em diversas localidades, potencializando as pesquisas em caráter histórico comparativas realizadas por projetos temáticos envolvendo grande número de pesquisadores nos diversos estados brasileiros. Por fim, são apresentados alguns exemplos de produções acadêmicas do grupo de pesquisa apoiados no uso do Repositório, tanto do ponto de vista de sua elaboração/produção assim como posterior divulgação/publicação.
\end{abstract}

Palavras-chave: História da educação matemática. Repositório. Fontes de pesquisa.

\section{THE DIGITAL CONTENT REPOSITORY IN THE RESEARCHES OF MATHEMATICS EDUCATION HISTORY}

\begin{abstract}
This article aims to presenting the Digital Content Repository used by GHEMAT - Grupo de Pesquisa de História da Educação Matemática. This virtual space, physically based at the Federal University of Santa Catarina, holds digital documents mobilized in the ongoing projects of this research group. Its use has been proved in a fruitful way as it allows the sharing of these sources in different locations, increasing comparative research in historical character performed by thematic projects involving large numbers of researchers in several Brazilian states. Finally, some examples of academic productions of the research group supported the use of the Repository are presented, both from the point of view of their development / production as well as subsequent dissemination / publication.
\end{abstract}

Keywords: History of mathematics education. Repository. Research sources.

\footnotetext{
${ }^{1}$ Este texto foi apresentado originalmente no IV Simpósio Iberoamericano : História, Educação, Patrimônio Histórico- Educativo em São Paulo/Centro Paula Souza, setembro, 2015.
} 


\section{CONSIDERAÇÕES INICIAIS}

As pesquisas históricas necessariamente se vinculam à elaboração de um projeto de trabalho no qual se define, a priori, o objeto inicial do estudo, seus recortes e possíveis associações, os métodos e técnicas empregadas, os tipos de fontes disponíveis, o período a ser estudado assim como todos os demais aspectos teórico-metodológicos da pesquisa.

Da mesma forma, as pesquisas em história da educação matemática trilham semelhante caminho. Segundo Pinto (2007), o primeiro grande problema a ser vencido ou superado que afronta o pesquisador da história da educação matemática é o fato do mesmo estar inserido num campo multidisciplinar que envolve Educação, Matemática e História. A indagação que comumente ocorre é: de que lugar está falando?

Mas como o pesquisador de educação matemática (majoritariamente professores de matemática) faz pesquisa em história da educação matemática? O que será necessário aprender com os historiadores para produzir história da educação matemática?

[...] para produzir história de um objeto cultural, [...] é fundamental apreender o sentido do fazer historiográfico. Isto se constitui um desafio para os que iniciam seu oficio de historiador. Primeiro, pelo imperativo da definição do lugar social de sua pesquisa; segundo, pela necessidade de conhecer e aprender a utilizar ferramentas conceituais advindas de outra matriz de conhecimento; terceiro, por deparar-se com diferentes abordagens de história. (PINTO, 2007, p. 110).

Uma das possíveis respostas desta pergunta pode ser encontrada na filiação das pesquisas realizadas no seio do GHEMAT - Grupo de Pesquisa de História da Educação Matemática, coordenado pelo Prof. Wagner Rodrigues Valente. Este grupo caracteriza-se, do ponto de vista de sua opção teórico-metodológica, por considerar que os estudos sobre história da educação matemática constituem um subconjunto das pesquisas que são desenvolvidas no âmbito da história da educação. Sendo assim, o grupo considera que suas pesquisas se filiam as especificidades da história.

Essa declarada opção por parte do grupo leva a um posicionamento no qual se rejeita a história como um modo de consolidar o passado. Ao perguntar sobre como questões da matemática escolar do presente foram naturalizadas, o historiador acaba por definir seu território de trabalho como sendo o da História da Educação.

Tal como em outros campos de conhecimento, como o da filosofia e da educação, a prática histórica da educação matemática requer a superação de uma busca de "verdade" naquilo que aconteceu num passado estático, sem ter que problematizá-lo a partir do presente, tomando o fato histórico como já construído, apenas à espera de uma descrição pontual do historiador. Por se tratar de um campo interdisciplinar, nele concorrem a história fornecendo ferramentas conceituais, a educação 
disponibilizando seu tempo histórico, a matemática fornecendo seus conteúdos. (PINTO, 2007, p. 111).

Muitas implicações para a prática da pesquisa decorrem da decisão de localizar os estudos históricos sobre a matemática escolar no campo da História da Educação. Há que se considerar como os historiadores da educação vêm trabalhando nas últimas décadas, qual lugar estão produzindo a sua história, quais os referenciais teóricos e quais fontes de pesquisa estão sendo mobilizados nas pesquisas para além de outras questões.

De acordo com o Diretório do Grupo de Pesquisas do $\mathrm{CNPq}^{2}$, o GHEMAT - Grupo de Pesquisa em História da Educação Matemática foi fundado em 2000 e reúne pesquisadores de diversos estados e universidades do Brasil. A atuação do grupo, segundo dados deste diretório, destaca-se pelo desenvolvimento coletivo de projetos temáticos de pesquisa sobre educação matemática nos diversos níveis de escolaridade. História do ensino de matemática, dos conteúdos escolares, dos livros didáticos, da disciplina Matemática e da formação de professores de matemática são alguns temas dos projetos.

Atualmente, o grupo é formado por 34 pesquisadores e 71 estudantes (doutorandos, mestrandos acadêmicos e profissionalizantes, além de alunos da graduação) integrados na linha de pesquisa do grupo cujo objetivo é desenvolver pesquisas com vistas à compreensão histórica do ensino e aprendizagem da matemática, da formação de professores de matemática e do trajeto de constituição da matemática escolar.

O compartilhamento das opções teórico-metodológicas pelos pesquisadores que compõem este grupo de pesquisa favorece que se operacionalize o desenvolvimento de projetos temáticos coletivos de pesquisa de história da educação matemática: as pesquisas são vetorizadas por projetos com diferentes dimensões estudadas pelo Grupo. Dado uma problemática, procura-se compreendê-la em sua articulação de contextos locais com aqueles mais amplos, sejam nacionais ou transnacionais.

Nesta direção, a partir do desenvolvimento do primeiro projeto temático ocorrido em 2006, outros pesquisadores-doutores tiveram interesse em compartilhar temáticas semelhantes de pesquisa. Como exemplo, pode ser citado o projeto de cooperação internacional entre Portugal e Brasil ${ }^{3}$. Desde esse tempo, na prática, o Grupo deixa de ser um coletivo pertencente a uma dada universidade, a um dado programa de pós-graduação e passa a se

\footnotetext{
${ }^{2}$ Para maiores informações ver em: <http://dgp.cnpq.br/dgp/espelhogrupo/2116509882385976>. Acesso em: 10 nov. 2015.

${ }^{3}$ O Projeto desenvolvido no âmbito do acordo de cooperação internacional CAPES-GRICES, intitulou-se "A Matemática Moderna nas escolas do Brasil e de Portugal: estudos comparativos". Reuniu diferentes universidades brasileiras e três instituições portuguesas (Escola Superior de Educação de Lisboa, Universidade de Lisboa e Universidade Nova de Lisboa).
} 
instituir como um conjunto de pesquisadores de diferentes instituições e programas de pósgraduação, em diversos estados brasileiros que levam adiante projetos coletivos de investigação (VALENTE, 2013).

E para além da estratégia da pesquisa mediada por projetos temáticos, mais recentemente, a organização coletiva dos pesquisadores em torno da construção de um espaço virtual para alocação dos documentos - que se tornarão fontes de pesquisa - denominado Repositório, torna-se a pedra fundamental que oportuniza e viabiliza o intenso diálogo entre as pesquisas em andamento. Seguindo este percurso metodológico, superam-se as tradicionais barreiras apresentadas pelas limitações geográficas, isto é, pesquisadores, por exemplo da região sudeste do Brasil tem acesso as fontes de pesquisas que estão sendo usadas simultaneamente na região norte do país e vice-versa. As distâncias geográficas entre regiões do país não se configuram mais como obstáculos a disseminação da pesquisa. Pelo contrário, o contínuo uso e alimentação deste espaço coletivo cria novas possibilidades de problematização, ampliando-se as escalas de análises, gerando um novo paradigma de fazer pesquisa histórica comparativa.

\section{O REPOSITÓRIO DE CONTEÚDO DIGITAL}

O Repositório constitui-se de espaço virtual no qual têm sido alocadas as fontes digitalizadas dos projetos coletivos de pesquisa. A construção de base de dados para fontes de pesquisa, por exemplo, não é inédita.

$\mathrm{Na}$ área de História da Educação Matemática, podemos citar alguns exemplos que tomam as mídias como o DVD para a disponibilização dos arquivos com as fontes utilizadas nas pesquisas que foram digitalizadas.

“A Educação Matemática na Escola de Primeiras Letras 1850-1960: um inventário de fontes" (2010) organizado pelo Prof. Dr. Wagner Rodrigues Valente e produzido pelo Grupo de Pesquisa de História da Educação Matemática (GHEMAT) ${ }^{4}$ trata-se de exemplo desta natureza. A elaboração deste inventário contou com a participação de diversos pesquisadores de distintas localidades e instituições e teve como propósito apresentar a digitalização de materiais relacionados à educação matemática nos primeiros anos da escolaridade. Revistas pedagógicas, livros didáticos, manuais de ensino, provas de alunos e legislação escolar constituem a base dessa documentação.

\footnotetext{
${ }^{4}$ Para maiores esclarecimentos ver <http://www2.unifesp.br/centros/ghemat/paginas/livros_CDs.htm>. Acesso em: 10 nov. 2015.
}

Rev. Iberoam. Patrim. Histórico-Educativo, Campinas (SP), v. 1, n. 1, p. 96-110, jul./dez. 2015 
Outros exemplos ainda podem ser citados, tais como: "A Matemática do colégio: livros didáticos para a história de uma disciplina" (2011). Trata-se de um DVD que possui uma base de dados de livros didáticos destinados ao curso colegial, desde o período da estruturação desse nível escolar (década de 1930) até finais do chamado Movimento da Matemática Moderna (1980). Um outro importante acervo encontra-se disponível em outro DVD "IV Congresso Brasileiro do ensino de Matemática Belém do Pará, 22 a 28 de julho de 1962” (2009). Desde 1955 tiveram início os Congressos do Ensino da Matemática. Bahia, Rio Grande do Sul, Rio de Janeiro, foram sedes dos primeiros encontros. Para o IV Congresso, Belém do Pará, foi o lugar escolhido. No entanto, diferentemente de outros congressos brasileiros, não foram publicados os Anais do Evento. Este $D V D$ tem por conteúdo a digitalização de parte da documentação amealhada do IV Congresso, e que se encontra fisicamente no Centro de Documentação do GHEMAT - Grupo de Pesquisa de História da Educação Matemática.

Tais exemplos ilustram a preocupação e algumas das ações efetivas do grupo de pesquisa na produção dos acervos visando a disponibilização das fontes para a comunidade acadêmica.

Mas estes exemplos citados, em alguma medida possuem limitações. As iniciativas das mídias digitais gravadas, por exemplo com o uso do DVD como suporte material, retrata esta limitação: para além da quantidade finita de informação, só terá acesso as informações aquele que possuir o $D V D$ gravado.

O Repositório constituindo-se como espaço virtual e disponibilizado na rede (internet) torna-se uma importante opção na qual têm sido alocadas as fontes digitalizadas dos projetos coletivos de pesquisa. Não em oposição as bases de dados já comentadas neste texto disponibilizadas em mídias como o $D V D$, mas de forma mais apropriada para esta finalidade, o Repositório assume como objetivo, por exemplo, a disponibilização das imagens digitalizadas de fontes primárias. O Repositório pode ser entendido como "uma forma de armazenamento de objetos digitais que tem a capacidade de manter e gerenciar material por longos períodos de tempo e prover o acesso apropriado" (VIANA et al., 2012).

Os repositórios digitais se filiam a uma área na qual se aplicam as tradicionais expertises da biblioteconomia em uma ambiência virtual. Fundamentalmente, o trabalho é semelhante aquele realizado numa biblioteca: catalogar, aspectos da curadoria, disseminação e preservação da informação. Mas na prática, o trabalho cotidiano é muito diferente, com implicações tanto nos recursos materiais quanto nos recursos humanos. Na pesquisa isso tem desdobramentos que passaremos a considerar adiante. 
O Repositório que acolhe as pesquisas do GHEMAT encontra-se "fisicamente" sediado na Universidade Federal de Santa Catarina, uma das diversas instituições de ensino e pesquisa na qual alguns membros do GHEMAT se filiam. Baseado na estrutura do DSpace $e^{5}$, com arquitetura simples e eficiente, utiliza-se de tecnologia de ponta e está direcionado ao acesso aberto, intencionalmente criado para esta finalidade.

A estrutura do Repositório constitui-se na forma de sub-unidades naturais e "comunidades" onde cada comunidade tem suas "coleções" que, por sua vez, contém "itens" que representam os conteúdos digitais. Todas estas informações são alimentadas por metadados ${ }^{6}$ que tem como finalidade facilitar a localização e recuperação das informações. $\mathrm{Ou}$ seja, todos os registros podem ser acessados por palavras chaves ou qualquer outro sistema de busca mais avançado (CAFÉ et al, 2003).

O Repositório em discussão neste artigo se alinha à sub-comunidade História da Educação Matemática, aninhada ao Centro de Ciências da Educação da UFSC. Trata-se de um repositório virtual, aberto e institucionalizado, especificamente para armazenar fontes diversas, ensaios e pesquisas voltadas para a História da Educação Matemática. Poderá ser consultado a partir de qualquer dispositivo com acesso à internet no seguinte endereço: <http://repositorio.ufsc.br/handle/123456789/1769>.

\footnotetext{
${ }^{5}$ DSpace é um software livre desenvolvido em parceria com MIT - Massachusetts Institute of Technology e a Hewlett Packard Corporation. Para maiores detalhes ver: COSTA, D. A.; ARRUDA, J. P. (2012)

${ }^{6}$ Para Clobridge (2010), metadado trata-se de qualquer informação sobre outra informação. No contexto dos repositórios, os metadados referem-se aos vários tipos de detalhes sobre o objeto incluindo neste caso seu uso e direitos, informações descritivas, dados estruturais, etc. No Repositório em discussão, os metadados são elementos de caracterização da fonte de pesquisa.
} 
Figura 1. Tela para acesso do Repositório de Conteúdo Digital.

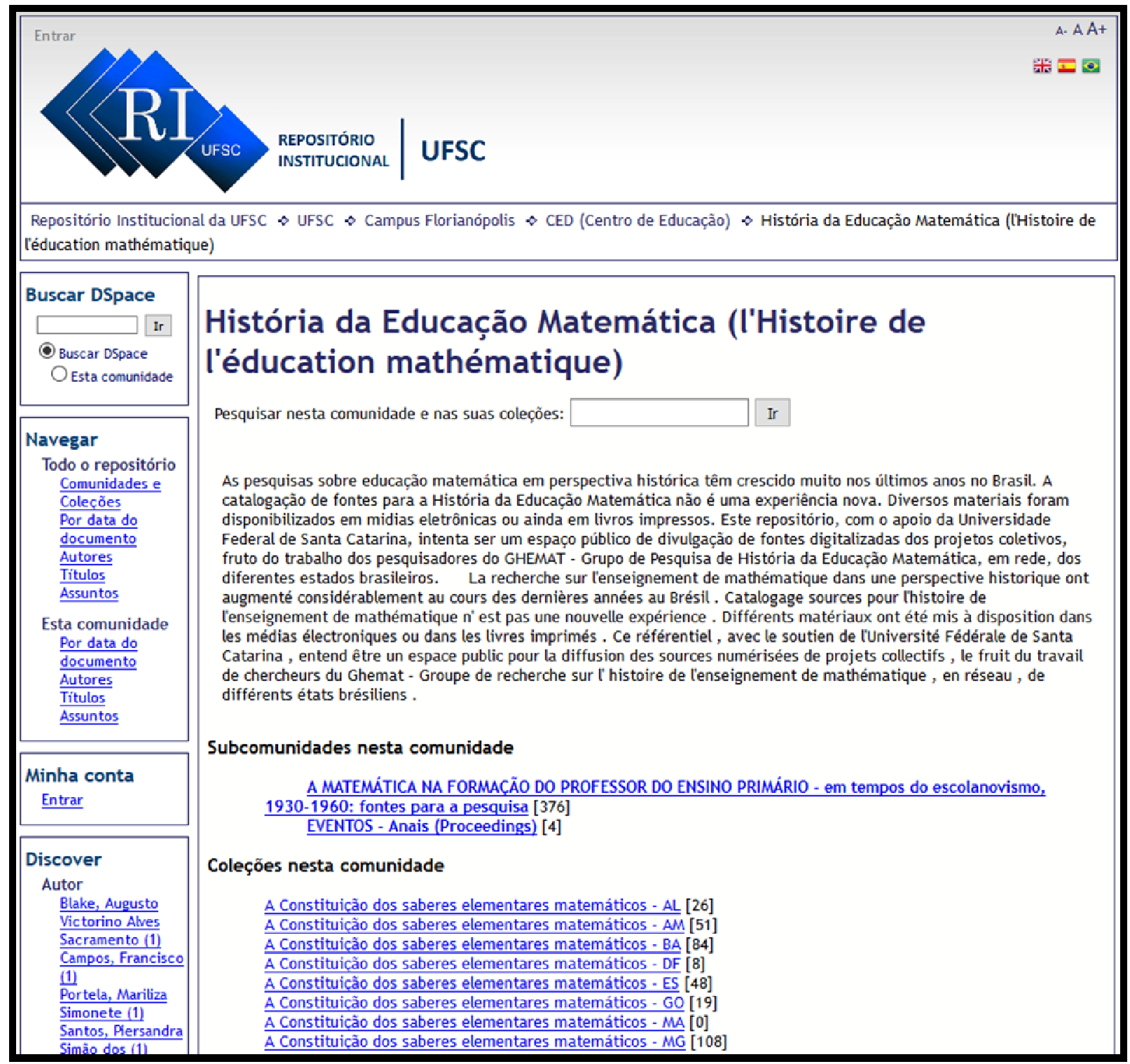

Fonte: <https://repositorio.ufsc.br/xmlui/handle/123456789/1769>. Acesso em: 10 nov. 2015.

Inicialmente o Repositório estava estruturado para algumas coleções, tais como: legislação escolar, livros didáticos, revistas pedagógicas, artigos acadêmicos, teses e dissertações.

As primeiras imagens/fontes de pesquisa que foram disponibilizadas no Repositório foram aquelas já distribuídas no DVD "Fontes para A Educação Matemática na Escola de Primeiras Letras 1850-1960: um inventário de fontes (2010)" organizado pelo Prof. Dr. Wagner Rodrigues Valente e produzido pelo Grupo de Pesquisa de História da Educação Matemática-GHEMAT. 
Para além de um simples repositório de imagens, como já informado, cada item inserido está associado aos metadados. Para o caso de livro didáticos, os metadados estão associados ao título da obra, ao nome dos agentes intervenientes (autores, editores, ilustradores, prefaciadores, etc), ano de edição, número da edição, informações acerca da citação, editor ou impressor, a descrição completa da correta citação normatizada (ABNT), descrição física da obra além da localização do exemplar que serviu para ser digitalizado, dentre outras coisas. Da mesma forma, exemplificamos alguns metadados para o caso da legislação escolar tais como o número da lei, ou decreto, ou regulamento, etc., o ano de sua emissão, nome do legislador (ou representante do governo), nome do estado, cidade, etc.

Cada item presente no Repositório está associado e identificado em seus respectivos metadados, o que permite os mecanismos de busca do DSpace operarem. A interface do Repositório com estes mecanismos de busca eletrônica promove que o pesquisador acesse a informação relativa ao item antes mesmo ter acessado suas imagens. O documento digital (item) somente é identificado se tiver os metadados corretamente associados. Diferentemente de um livro que sempre poderá ser folheado, os itens digitais somente podem ser acessados no Repositório por intermédio dos metadados que identificam e o localizam precisamente. Isso se torna possível dada a correta e boa descrição dos metadados elaboradas pelos próprios pesquisadores do GHEMAT ao incluírem os documentos na base de dados do Repositório.

Talvez este seja um dos pontos mais importantes na caracterização do Repositório. Na medida que o pesquisador elege um dado documento para ser introduzido no Repositório, transforma-se o estatuto deste documento com seu uso em fonte de pesquisa. E como tal, ele deve estar muito bem caracterizado permitindo a catalogação de forma que seja possível facilmente identificá-lo pelos mecanismos de buscas. Dito de outra forma, o documento encontrado por um determinado pesquisador, no seu local de trabalho, e inserido no Repositório, por exemplo, torna-se imediatamente de domínio e uso da coletividade. Isso representa um salto qualitativo em pelo menos dois níveis: para catalogar um item, este deve ser exaustivamente estudado e caracterizado - o que implica um trabalho intenso de análise sobre o documento deixando um grande legado de conhecimento e informação acerca dessa fonte para quem o depositou (no caso para o pesquisador que encontrou o documento originalmente e construiu os seus metadados). O segundo nível, está no uso do Repositório e do documento inserido, transformado em fonte de pesquisa por qualquer outro pesquisador. Por meio da boa caracterização referenciada pelos metadados, qualquer pesquisador ao acessar o Repositório se apropria do item contextualizado por meio da leitura dos seus 
respectivos metadados antes mesmo do acesso às imagens do documento. Os metadados constituem, desse modo, uma espécie de biografia do documento (COSTA, 2015).

Mais do que ser um fichamento com os dados básicos de uma dada fonte de pesquisa digitalizada (item do repositório), o cadastramento passa a ser elemento ativo no processo da pesquisa que se desenvolve no grupo alcançando um novo estatuto no trabalho coletivo. $\mathrm{O}$ item depositado, junto com seus metadados no Repositório, não é só "produto final” de uma dada pesquisa, mas sim elemento inicial de outras novas pesquisas.

E essa dinâmica de trabalho assumida por todos os pesquisadores do GHEMAT ao fazer uso do Repositório, cria um novo paradigma para as pesquisas históricas em educação matemática em âmbito nacional, quiçá transnacional, dado a mobilidade destes dados fomentados pelos interesses comuns de pesquisa orquestrados nos projetos temáticos em andamento no interior do Grupo.

\section{A PESQUiSA EM HISTÓRIA DA EDUCAÇÃO MATEMÁTICA NO GHEMAT EM MOVIMENTO PELO REPOSITÓRIO: ALGUNS EXEMPLOS}

A realização dos projetos temáticos coletivos impõe aos participantes do Grupo o estabelecimento de acordos, de consensos para que haja viabilidade nesse tipo de trabalho. No caso da pesquisa individual, ou ainda aquela que reúne um professor orientador e seus orientandos, estas podem livremente se movimentar deixando a lógica da investigação presidir o processo da pesquisa. No caso das pesquisas coletivas, é imperativo o estabelecimento de passos, de etapas conjuntas de trabalho que envolvam a seleção de temas e fontes que potencializem o diálogo entre os diferentes participantes do projeto.

Em geral, os projetos têm suas durações limitadas em três, quatro anos para serem concluídos, e a dispersão das pesquisas feitas livremente pelos diversos pesquisadores inviabilizariam as trocas entre os diferentes grupos. Há que existir uma organização do trabalho que contemple, resumidamente falando, temas comuns de pesquisa e, em cada etapa, que estes temas sejam abordados por meio de determinado tipo de fontes.

Atualmente, no GHEMAT, está em curso o desenvolvimento do projeto temático “A Constituição dos Saberes Elementares Matemáticos: a Aritmética, a Geometria e o Desenho no curso primário em perspectiva histórico-comparativa, 1890-1970" - projeto apoiado pelo CNPq (Edital Universal CNPq 470400/2012-9). Intenta-se com este projeto a elaboração de uma investigação histórico-comparativa, cuja temática relaciona-se à análise da trajetória de 
constituição dos saberes elementares matemáticos presentes no curso primário de diferentes regiões do país.

A organização desses saberes elementares matemáticos revelam-se em várias instâncias: nas diretrizes curriculares oficiais; nos impressos pedagógicos para professores, nas revistas com orientações didáticas para o ensino; nos relatórios de estágio docente; nos manuais e livros didáticos; nos documentos de elaboração de aulas dos professores; nos materiais dos alunos (cadernos, fichas etc.); na docimologia escolar (exames, provas e testes de aferição da aprendizagem) dentre muitos outros documentos ligados ao funcionamento do cotidiano escolar de outros tempos. O estudo histórico-comparativo considera essa multiplicidade de fontes para a pesquisa, em atual fase de inventário nos diferentes estados brasileiros, pelos grupos locais participantes da pesquisa.

O projeto previa a sua realização em três etapas levando-se em conta a especificidade das fontes a serem utilizadas. Cada etapa foi subdividida em subprojetos de pesquisa. Esses subprojetos, por sua vez, ramificaram-se noutros projetos, atendendo a determinados níveis e períodos, contidos na extensão da pesquisa, dado a diversidade dos trabalhos empreendidos nos diversos estados brasileiros. Assim, no primeiro ano de realização da investigação foram privilegiadas como fontes de pesquisa a documentação oficial para o ensino de matemática e os impressos pedagógicos. De forma preliminar, divididos nos estados brasileiros, estas documentações já se encontram disponíveis no Repositório. No ano seguinte do andamento do projeto, a ênfase do estudo estaria associada nos manuais pedagógicos para professores e nos livros didáticos utilizados pelos alunos; para em seguida, no próximo ano, a pesquisa se debruçar nos documentos contidos em arquivos escolares. Esta organização anual dos trabalhos, em termos de privilegiar fontes em cada etapa, foi a solução adotada atendendo a aspectos organizacionais, de modo a melhor conduzir as discussões comparativas realizadas entre as equipes de trabalho dos diferentes estados brasileiros envolvidos no projeto.

Dessa exposição, depreende-se que o Repositório abriga uma coleção criada especialmente para ser alimentada por documentos/fontes relacionada a este projeto de pesquisa estruturado pelos estados da federação. Em seu texto original integravam-se quatorze pesquisadores de dez estados brasileiros, a saber: AL, MG, MT, PR, RJ, RN, RS, SE, SC, SP. No entanto, atualmente, encontramos pastas que se relacionam a outros estados da federação, para além dos iniciais elencados, tais como: AM, BA, DF, ES, GO, MA, PA e RR. Tal situação é resultada da dinâmica inclusiva de novos pesquisadores a rede do GHEMAT que compartilham mesmos interesses de pesquisa, contribuindo de forma bastante eficaz para a ampliação do conhecimento e das pesquisas na área. 
A partir da disponibilização destes documentos que se transformam em fonte de pesquisa por seu uso, é possível estabelecer múltiplas conexões. O Repositório tem se constituído como importante ferramenta que permite uma real possibilidade de diálogo entre grupos de pesquisa interessados na produção de conhecimento em nível nacional, tomando em vista a empiria local. Concretamente, recente resultado de pesquisa que privilegiou o Repositório como um dos principais acervos de pesquisa, é a tese de doutoramento de Mariliza Simonete Portela ${ }^{7}$.

Sua pesquisa está inserida no GPHDE - Grupo de Pesquisa de História da Educação Matemática, sediado e vinculado ao PPGE - Programa de Pós-Graduação em Educação da Pontifícia Universidade Católica do Paraná (PUC/PR). Este grupo tem como objetivo de estudo a história das disciplinas escolares e investiga reformas e movimentos que marcaram o currículo escolar, os saberes docentes, a constituição e as finalidades das diferentes disciplinas escolares, ao longo do século XX, no Brasil. Observa-se, a partir deste exemplo, que sua pesquisa dialoga com o projeto temático em curso no GHEMAT.

Portela (2014) abordou em sua tese a circulação e apropriação do material didático denominado "Cartas de Parker" - conjunto de 48 gravuras para o ensino de aritmética, originário dos EUA, editado no Brasil a partir de 1902, tendo como fundamento o método intuitivo.

A adoção deste material didático em diferentes províncias/estados brasileiros foi constatada pela pesquisadora analisando a documentação oficial alocada na base de dados do Repositório. Um modelo pedagógico para o ensino de aritmética nos anos iniciais escolares em muito se deveu à circulação e apropriação desse material pedagógico, cuja análise somente foi possível em razão do acesso fácil, rápido e eficaz à documentação de época de cerca de duas dezenas localidades que cobrem o território nacional. O modelo cultural pedagógico materializado nas Cartas de Parker teve circulação e apropriação em mais da metade das províncias/estados brasileiros, localizados em diversas regiões do país (COSTA; VALENTE, 2015).

A pesquisa descrita que se apoiou nos documentos presentes no Repositório encontra-se disponível também na pasta “Teses e Dissertações em História da Educação

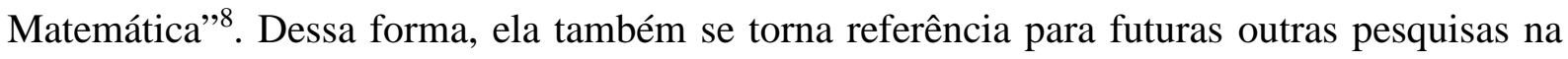
área.

\footnotetext{
${ }^{7}$ Disponível em <https://repositorio.ufsc.br/handle/123456789/128465>. Acesso em: 10 nov. 2015.

${ }^{8}$ Para maiores detalhes ver em: 〈https://repositorio.ufsc.br/handle/123456789/1791〉. Acesso em: 10 nov. 2015.
} 
Um exemplo diverso pode ser observado também nas produções parciais do grupo GHEMAT frente as etapas das pesquisas. O Grupo utiliza-se do expediente denominado Seminário Temático. A realização de Seminários Temáticos pelos membros deste grupo de pesquisa tem-se revelado como importantes momentos de discussão e reflexão acerca dos resultados parciais que vêm sendo obtidos com a realização dos projetos de estudos compartilhados. Florianópolis, em Santa Catarina, localizada na região Sul do Brasil, sediou sua décima primeira edição em abril de $2014^{9}$.

As discussões ocorridas neste seminário materializaram-se em obra organizada por Costa e Valente (2014), "Saberes matemáticos no curso primário: o que, como e por que ensina? Estudo histórico-comparativos a partir da documentação escolar". Tratou-se das avaliações e reflexões da primeira fase do projeto temático em curso que privilegiou as fontes normativas em todas as unidades da federação.

Cabe esclarecer que esta obra foi idealizada para que todos os documentos referendados nela estivessem disponíveis no Repositório. A análise da documentação oficial/programas de ensino permitiu a elaboração dos diversos capítulos desta obra. Dessa forma, o intensivo cotejamento das fontes permitido pelos links ativos do Repositório conduz o leitor pari passu às fontes primárias, que contribuem na compreensão desta história da educação matemática que se deseja produzir.

Assim como na publicação impressa, a edição eletrônica ${ }^{10}$ desta obra também disponível no formato epub se alinha com a mudança na escrita da história, não só pela possibilidade quantitativa de tratamento de grandes volumes de informação permitida pelo uso do Repositório, mas principalmente pelas novas modalidades de construção, publicação e recepção dos discursos históricos (COSTA; VALENTE, 2014).

Dito de outra forma, Chartier (2010) chama a atenção para estas mutações que impõe a história o ingresso na era da textualidade eletrônica: a maneira de organizar as argumentações, históricas ou não, os critérios que podem mobilizar o leitor para aceitá-las ou rejeitá-las são alguns dos exemplos. Do ponto de vista do historiador, de quem escreve a história, permite-se desenvolver demonstrações segundo uma lógica que já não é necessariamente linear ou dedutiva, como é a que impõe a inscrição de um texto em uma página. Permite uma articulação aberta, fragmentada, relacional do raciocínio, tornada possível pela multiplicação das ligações hipertextuais. Do ponto de vista do leitor, a validação

\footnotetext{
${ }^{9}$ Ver anais em: <http://seminariotematico.ufsc.br/>. Acesso em: 10 nov. 2015.

${ }^{10}$ Versão ebook disponível em: <https://repositorio.ufsc.br/handle/123456789/133058>. Acesso em: 10 nov. 2015.
} 
ou rejeição de um argumento pode se apoiar na consulta direta do texto (no caso do Repositório - das imagens que reproduzem os documentos) que é o próprio objeto de estudo. Sendo assim, o leitor já não é mais obrigado a acreditar no autor e pode refazer total ou parcialmente seu próprio percurso da pesquisa (CHARTIER, 2010).

Um último ponto que merece destaque ainda sobre o uso do Repositório é a sua flexibilidade e agilidade na disponibilização das informações e resultados. Recentemente ocorreu um evento científico "Colloque international Franco-Brésilien portant sur l'enseignement des mathématiques à l'école primaire, XIXe.-XXe. siècle" na Universidade de Limoges, França em maio de 2015. Este colóquio foi motivado para socializar resultados parciais de outro projeto temático ${ }^{11}$ em curso no GHEMAT com pesquisadores desta universidade que acolheu o evento juntamente com outros pesquisadores da Université ParisSUD.

Antes mesmo do final deste evento, presente no Repositório, encontravam-se disponíveis as imagens utilizadas nas apresentações utilizadas pelos pesquisadores ${ }^{12}$. E estas apresentações circularam em diferentes outros sitios tais como a l'Académie de Limoges e l'IREM - Institut de Recherche sur l'Enseignement des Mathématiques, ambos de Limoges ${ }^{13}$.

\section{CONSIDERAÇÕES FINAIS}

Esta comunicação procurou trazer a lume o uso do Repositório de Conteúdo Digital realizado pelo GHEMAT na produção das pesquisas no âmbito da história da educação matemática. Os documentos mobilizados nas pesquisas que se tornam fontes podem não fazem parte mais exclusivamente dos arquivos públicos, ou ainda de bibliotecas, museus, centros de memória e/ou de documentação. As digitalizações dos mesmos e a disponibilização em bancos de dados digitais alteram, de forma significativa, as maneiras de fazer da pesquisa histórica.

\footnotetext{
11 Trata-se do projeto temático: "O ensino de matemática na escola primária nos séculos XIX-XX: estudos comparativos entre o Brasil e a França". Este projeto é apoiado pela CAPES-COFECUB (Coordenação de Aperfeiçoamento de Pessoal de Nível Superior - Comité Français d' Évaluation de la Coopération Universitaire et Scientifique avec le Brésil) e possui o prof. Wagner Rodrigues Valente (GHEMAT) como coordenador da parte do Brasil e o Prof. Renaud D’Enfert (GHDSO - Université Paris SUD)

${ }_{12}$ Ver as apresentações disponíveis em: 〈https://repositorio.ufsc.br/handle/123456789/133245>. Acesso em: 10 nov. 2015.

${ }^{13}$ Ver os links disponíveis em: <http://espe.unilim.fr/colloque-international-lenseignement-desmathematiques-a-lecole-primaire-xixe-xxe-siecle/> e < http://www.irem.unilim.fr/infos/rencontresscientifiques/>. Acesso em: 10 nov. 2015.
} 
E não somente a própria produção da história, mas também as novas possibilidades de divulgação dos seus resultados. Se antes os textos impressos ditavam a lógica das exposições científicas, a partir dos textos eletrônicos produzidos relacionados com as fontes de pesquisa inseridas no Repositório, tudo é passível de ser verificado, confrontado, criticado, questionado, interrogado.

A utilização dos ebooks nas divulgações científicas apoiadas no uso do Repositório potencializam novas formas de produção da história da educação matemática.

Muitos outros desdobramentos surgirão desta inovadora prática de fazer e posteriormente de divulgar os resultados da pesquisa, uma vez que a própria divulgação dentro deste formato já é elemento de potencialização de novas pesquisas.

Descreve-se, desta forma, uma mudança epistemológica fundamental que transforma profundamente as técnicas de provas e das modalidades de construção e validação dos discursos de saber.

\section{REFERÊNCIAS}

CAFÉ, L.; MÁRDERO ARELlANO, M. A.; BARBOZA, E. M. F.; MELO, B. A.; NUNES, E. M. A. Repositórios Institucionais: nova estratégia de publicação científica na rede. In: ENDOCOM, 13, Belo Horizonte, MG. Anais... Belo Horizonte, MG. 2003.

CHARTIER, R. A história ou a leitura do tempo. Belo Horizonte: Autêntica, 2010.

CLOBRIDGE, A. Building a Digital Repository Program with limited resources. Oxford: Chandos Publishing, 2010.

COSTA, David Antonio da; ARRUDA, Joseane Pinto de. Repositório institucional de fontes para a história da educação matemática na Universidade Federal de Santa Catarina. In: I Encontro Nacional de Pesquisa em História da Educação Matemática, 1, 2012. Vitória da Conquista. Anais... Vitória da Conquista: UESB, 2012.

COSTA, D. A. Repositório. In: VALENTE, W.R. (Org.). Cadernos de Trabalho, v. 3, São Paulo: Livraria da Física, 2015.

COSTA, D. A.; VALENTE, W. R. (Orgs.). Saberes matemáticos no curso primário: o que, como e por que ensinar? Estudos histórico-comparativos a partir da documentação oficial escolar. São Paulo: Ed. Livraria da Física, 2014.

Saberes matemáticos no curso primário: o que, como e por que ensinar? Estudos histórico-comparativos a partir da documentação oficial escolar. São Paulo: Ed. Livraria da Física, 2014. Em linha (ebook): <https://repositorio.ufsc.br/handle/123456789/133058>. Acesso em: 10 nov. 2015. 
História da Educação Matemática e o uso de um Repositório de conteúdo digital. São Paulo: Livraria da Física, 2015 (Série história da matemática para o ensino; v.4)

PORTELA, M. S. As Cartas de Parker na matemática da escola primária paranaense na primeira metade do século XX: circulação e apropriação de um dispositivo didático. 2014. 190f. Tese (Doutorado em Educação) - Pontifícia Universidade Católica do Paraná. Escola de Educação e Humanidades. Programa de Pós-Graduação em Educação, Curitiba, PR.

PINTO, N. B. O fazer histórico-cultural em Educação Matemática: as lições dos historiadores. In: SEMINÁRIO DE HISTÓRIA DA MATEMÁTICA, 7, 2007. Guarapuava. Anais... Guarapuava: Universidade do Centro-Oeste, p. 109-127, 2007.

VALENTE, W. R. Oito temas sobre história da educação matemática. REMATEC. Natal, RN, v. 8, n. 12, jan./jun. 2013.

VIANA, C. L. M.; MÁRDERO ARELLANO, M. A.; SHINTAKU, M. Repositórios institucionais em ciência e tecnologia: uma experiência de customização do DSpace. In: SIMPÓSIO DE BIBLIOTECAS DIGITAIS, 3, 2005, São Paulo. Anais... São Paulo: CRUESP, 2005. Disponível em: <http://bibliotecas-cruesp.usp.br/3sibd/docs/viana358.pdf>. Acesso em: 10 nov. 2015. 